\title{
The relationship between stochastic and temporal dominance under an accuracy set ${ }^{1,2}$
}

WILLIAM M. PETRUSIC 3 UNIVERSITY OF MICHIGAN

The method of replicated paired-comparisons was utilized to obtain estimates of response consistency and mean re$s$ ponse latency for both preferential choices for two outcome gambles and judgmental choices of the riskiness of these bets. The results indicate that under an accuracy set stochastically-dominant choices have a shorter mean latency than stochastically-non-dominant choices. The implications of this result for mathematical models of response latency are considered.

Mathematical models for latency of choice have implications for the relationship between the latencies associated with two classes of choices. These classes are defined below.

(1) Stochastic-Dominance (SD): $S_{j}(S D) S_{j} \equiv \operatorname{Pr}\left[S_{j}>S_{j}\right]>\operatorname{Pr}\left[S_{j}>S_{j}\right]$. $S_{j}$ is called the stochastically-dominant $(S D)$ choice in the $\left(S_{i}, S_{j}\right)$ (where $S_{j}>S_{j}$ denotes that $S_{j}$ is picked in the pair $\left(S_{i}, S_{j}\right) . S_{j}$ is called the stochastically-non-dominant (SND) choice in the pair $\left(S_{i}, S_{j}\right)$. When $\operatorname{Pr}\left[S_{j}>S_{j} l^{\prime}=\operatorname{Pr}\left[S_{j}>S_{i} !\right.\right.$ then $S_{i}$ and $S_{j}$ are called stochastically-equivalent (SE). The entire set of choices for which $S_{j}$ is $S D$ over $S_{j}$ will be denoted $\left\{S_{j}(S D) S_{j}\right\}$.

An analogous definition can be given for response latency and is given by:

(2) Temporal-Dominance (TD): $S_{j}(T D) S_{j}=\bar{L}\left(S_{j}>S_{j}\right)<T_{-}\left(S_{j}>S_{j}\right)$ (where $\bar{L}\left(S_{j}>S_{j}\right)$ denotes the mean latency associaited with the set of choices when $S_{j}$ is picked in the pair $\left(S_{i}, S_{j}\right) . S_{j}$ is called the temporally-dominant (TD) choice in the pair $\left(s_{j}, s_{j}\right)$ and $S_{j}$ the temporally-non-dominant (TND) choice. When $\bar{L}\left(S_{i}>S_{j}\right)=\bar{L}\left(S_{j}>S_{j}\right)$ then $S_{i}$ and $S_{j}$ are called temporaily equivalent (TE).

This report is concerned with the relationships of (1) and (2) under an explicit non speed set (accuracy orientation) in both preferential and judgmiental choice behavior. It is hypothesized that the following relation will hold:

(R1): (SD) $\leftrightarrow$ (TD), that is, the mean latency of the set of (SD) choices will be shorter than those of the (SND) set.

The models of Luce (1959), La Berge (19t.2), initsoh (1963), and Audley (1960) predict that (R1) will boird. On the other hand, a model presented by Estes (1.958) loads to the prediction that (R1) will not hold, in that SD choices will occur with longer mean latencies than thuse. of the SND set. Finally, models presented by Cartwright and Festinger (1941), and Bower (1959) (observational model A) predict that SD and SND cheices a co " $\mathrm{CL}$.

The experimental literature on (RI) is inyiting but clear. (See Petrusic, 1966, for a report on this stera- ture.) Greenberg (1961) has suggested that (R1) may hold under an accuracy orientation, and not hold under a speed orientation. Coombs and Torgerson (see Coombs, 1964) have provided a theoretical rationale for how this may in fact occur.

\section{Method}

Subjects. The Ss for this experiment were two female senior citizens from Ann Arbor. One $S$ was 64 years old, the other 70 years old.

Stimuli. The stimuli for this experiment were two outcome bets with positive and negative outcomes. This set of gambles has the following properties:

(i) For each bet, E.V. $=1 / 2 \mathrm{~V}^{1 / 2}$ (where E.V. and V denote Expected Value and Variance respectively).

(ii) E.V. and V were perfectly negatively correlated (rank order) with Skewness (S).

The constraints within such a set of gambles necessitate that as the gambles become more negatively skewed and E.V. and $\mathrm{V}$ increase, the amount of the loss outcome (Lo) also increases. Thus, E.V., V, S, and Lo are all perfectly confounded. There were nine gambles in the set.

Procedure. Ss were given two choice tasks:

A. Ss were asked to indicate which of two bets they preferred (Task A), and

B. Ss were asked to judge which of two bets they thought was riskier (Task $B$ ).

At the end of every $15 \mathrm{~min}$. Ss played one of their preferred gambles from a randomly selected pair of a mbles. Ss were paid in poker chips, which they casined in at the end of every 2-hr. session. For Task A 30 and 24: replications were obtained for Ss 1 and 2, respectively, and for Task B, 20 and 16.

The stimulus pairs were projected on a screen and the Ss made their choices by pressing one of two buttons. The S's response and its latency were automatically punched on an IBM card.

The portion of the instructions relevant to the induction of a non speed set are given below:

On the card you will notice that the time you took to decide has also been recorded. However, there is no reason to make your decisions quickly, in fact, it is best if you take as much time as you wish, so that you can make you choices carefully and consider overything that looks important to you.

\section{Results}

Table 1 indicates the frequencies with which (R1) holds according to $S$ and task. The totals in Table 1 iiffer over ss and between tasks because there were inst:mees in which there were either no non-dominant 
Table 1. Relation between Stochastic and Temporal Dominance for stimuli for which $0.50<\operatorname{Pr}\left[S_{i}>S_{j}\right]<1.00$

\begin{tabular}{|c|c|c|c|}
\hline \multirow[b]{2}{*}{ Task } & \multicolumn{3}{|c|}{ Subject 1} \\
\hline & $\begin{array}{l}\bar{L}\left\{S_{i}(S D) S_{j}\right\} \\
\bar{L}\left\{S_{i}(S N D) S_{j}\right\}\end{array}$ & $\begin{array}{l}\bar{L}\left\{S_{i}(S D) S_{i}\right\rangle \\
{\left[\left\{S_{i}(S N D) S_{j}\right\}\right.}\end{array}$ & Total \\
\hline $\begin{array}{l}\text { A (preference) } \\
\text { B (riskiness) } \\
\text { Total }\end{array}$ & $\begin{array}{l}25 \\
21 \\
46\end{array}$ & $\begin{array}{l}4 \\
5 \\
9\end{array}$ & $\begin{array}{l}29 \\
26 \\
55\end{array}$ \\
\hline
\end{tabular}

\begin{tabular}{ccc}
\multicolumn{3}{c}{ Subject 2} \\
{$\left[\left\{S_{i}(S D) S_{i} k\right.\right.$} & $\left.L I S_{i}(S D) S_{i}\right\rangle$ & Total \\
{$\left[\left\{S_{i}(S N D) S_{i}\right\}\right.$} & $L\left\lfloor S_{i}(S N D) S_{i}\right\}$ & \\
27 & 4 & 31 \\
15 & 10 & 25 \\
42 & 14 & 56
\end{tabular}

choices or $S_{i}(S E) S_{j}$. The hypothesis that the frequency that (R1) is satisfied is equal to the frequency that (R1) fails to hold was rejected $\left(X^{2}=13.79 ; d f=1 ; 0.001>p>\right.$ 0.0005 ) for both Ss, Task $A$, and $S 1$, Task B, but not for S 2, Task B.

\section{Discussion}

The results strongly suggest that under an accuracy set (orientation) (R1) holds, and thereby greatly delimiting the class of choice models compatible with the data. If it can also be shown that under a speed set (R1) does not hold then either a more general model which incorporates response set must be constructed or some rationale must be provided for why one class of models is appropriate under a given response set and not under a different response set.

It should be noticed in Table 1 that there are cases where SND choices have shorter response latencies than the SD choices. This in fact occurred for stimulus pairs where the SND choice probability was extremely low (between 0.05 and 0.10 ). The means of these choices are thus based on an extremely small number of observations and thus may be rather unreliable. However, such choices appear to be accompanied by extremely rapid latencies (in relation to those pairs for which (R1) holds). It is, also, exactly these pairs which lead to significant violations of a strictly monotone relationship between response probability and response latency in much the same way as Luce (1959) found in his analysis of Kellog's (1931) data and as occurred in Henmon's (1911) data. It may be that in some manner choices on these particular pairs are made under a non accuracy set while those pairs for which (R1) holds are made under an accuracy set, and it is this differential response set that leads to a non-monotone relationship between response consistency and latency. Further, systematic work on the effects of differential response set must be done before the relationship of response consistency and response latency can be precisely specified.

\section{References}

Audley, R. J. A stochastic model for individual choice behavior. Psychol. Rev., 1960, 67, 1-15.

Bowrer, G. H. Choice-point behavior. In R. R. Bush \& W. K. Estes (Eds.), Studies in mathematical learning theory. Stanford, Calif.: Stanford University Press, 1959. Pp. 109-124.

Cartwright, D., \& Festinger, L. A quantative theory of decision. Psychol. Rev., 1941, 48, 425-442.

Coombs, C. H. A theory of data. New York: Wiley, 1964.

Estes, W. K. A model for choice behavior. Presented at the University of Michigan seminar on the application of mathematics to the social sciences. Dittoed notes, 1958.

Greenberg, M. Response latency as a test of mathematical models for preference behavior. Unpublished Ph.D. dissertation. University of Michigan, 1961.

Henmon, V. A. C. The relation of time of judgment to its accuracy. Psychol. Rev., 1911, 18, 186-201.

Kellog, W. N. The time of judgment in psychometric measures. Amer. J. Psychol., 1931, 43, 65-86.

Kintsch, W. A response time model for choice behavior. Psychometrica., 1962, 28, 27-32.

La Berge, D. A recruitment theory of simple behavior. Psychometrica., 1962, 27, 375-396.

Luce, R. D. Response latencies and probabilities. In K. Arrow, S. Karlin \& P. Suppes (Eds.) Mathematical methods in the social sciences. Stanford, Calif.: Stanford University Press, 1959.

Petrusic, W. M. Choice response latency: A review of the empirical literature. Unpublished mimeo report, 1965.

\section{Notes}

1. This work was supported in part by USPHS Grants MH 04236 (CI), and NIH TI GM 1231-01.

2. This report has profited greatly from the encouragment and criticism of Dr. Robyn M. Dawes and also from Dr. Clyde $\mathrm{H}$. Coombs, who directed the decision making study of which the data presented here are a part. The assistance of Frank Goode is also appreciated.

3. Now at the Department of Psychology, University of British Columbia. 